\title{
A contribution to the understanding of pain in fibromyalgia based on cerebrospinal fluid investigations
}

\author{
Henning Værøy MD DrMedSci
}

\begin{abstract}
H Værøy.
A contribution to the understanding of pain in fibromyalgia based on cerebrospinal fluid investigations.

Pain Res Manage 1996;1(1):45-49.

Fibromyalgia is established in current practice as a condition with widespread pain and a number of specific tender points, as well as symptoms of limb stiffness, lack of refreshing sleep and depression. Musculoskeletal correlations with the syndrome have generally been disappointing. Chemical changes in the cerebrospinal fluid are of interest and seem to show significant relationships with fibromyalgia, both with respect to opioid peptides and substance $P$. The nature of these relationships and their possible linkage with neuronal plasticity at the spinal cord level are discussed. The influence of both peripheral sensitization and reduced presynaptic inhibitory feedback is considered in this connection.
\end{abstract}

Key Words: Cerebrospinal fluid, Dynorphin, Fibromyalgia, Opioid peptides, Substance P

\section{Une contribution à la compréhension de la douleur dans la fibromyalgie basée sur des analyses du liquide céphalorachidien}

RÉSUMÉ : La fibromyalgie est en pratique courante définie comme une affection associée à une douleur diffuse et à plusieurs points douloureux spécifiques, ainsi qu'à des symptômes de raideur des membres, à l'absence de sommeil réparateur et à la dépression. Les corrélations musculo-squelettiques avec ce syndrome ont généralement été décevantes. Des changements chimiques dans le liquide céphalorachidien semblent un champ intéressant et suggèrent l'existence de relations significatives avec la fibromyalgie, à la fois en rapport avec les peptides opioïdes et la substance P. La nature de ces relations et leurs associations possibles avec une rigidité plastique neuronale au niveau de la moelle épinière sont examinées. L'influence combinée d'une sensibilisation périphérique et d'une rétroaction présynaptique inhibitrice réduite est envisagée à ce propos.
$\mathrm{I}_{2}^{\mathrm{th}}$ thas been estimated that fibromyalgia occurs in approximately $2 \%$ of the general population, although this number varies in different studies. According to the latest criteria, it is a generalized chronic pain condition (1). Other features often reported are limb stiffness, lack of refreshing sleep and depression (1).

Fibromyalgia is classified as a soft tissue rheumatic disorder (1). The resemblance between symptoms seen in fibromyalgia and those seen in some of the other rheumatic complaints is evident, especially when it comes to pain description and pain localization (2). In addition to specific soft tissue tender points, fibromyalgia patients often describe their pain as being widespread with an aching and burning sensation (2). Studies have been attempted to reveal the pathophysiology of the tender points; however, no distinct pathognomic findings have been found so far. Using light microscopy, nonspecific changes like ragged red fibres and fibres with a 'moth-eaten' appearance have been described (3). Electron microscopy studies have also failed to demonstrate any specific findings (3). The moth-eaten appearance has been interpreted by some as cell destruction due to ischemia; one study has shown that there seems to be a reduction of high energy phosphate in the tender points, indicating lower 
oxygen dependent cellular metabolism (4). Other studies have looked at the sympathetic nervous system regulation of the microcirculation in patients with fibromyalgia $(5,6)$. The results from these studies indicate a sympathetic nervous system dysfunction in these patients; these studies also showed that the results from the percutaneous recordings used were probably disturbed by factors between the skin and the microvascular recording site $(5,6)$.

Animal studies have shown that cerebrospinal dynorphin mRNA is increased after inducing an inflammatory pain condition $(7,8)$. Although it may be hazardous to apply interpretations of results from animal studies directly to those from human studies, elevated levels of dynorphin $\mathrm{A}$ in the cerebrospinal fluid (CSF) of patients with fibromyalgia may indicate an inflammatory contribution. Whether a tender point represents hyperalgesia or allodynia has not been studied sufficiently; however, the impression after examining these patients is that unharmful/nonnoxious stimuli may be sufficient to elicit pain.

Why then look at neuropeptides in a condition like fibromyalgia? First, the only true common symptom these patients present is chronic pain (1). Pain is a central nervous system (CNS) phenomenon even though the onset may be related to a peripheral event. Synaptic activity and modulation depend on different neurotransmitters which also influence the transmission of pain impulses and their modulation (9). To apply the present knowledge in clinical situations we must allow for unknown processes which can affect peptides between the time of secretion from the synapses and the time of lumbar extraction. Enzymatic activity is an example of such a process. Therefore, the volume secreted may not necessarily be identical to the volume extracted. Regardless of these uncertainties one of the hypotheses for doing these pilot studies on human CSF is that the peptide levels measured may reflect important aspects of 'yesterday's' transmissions. Accordingly, if a condition is relatively stable the stability makes the condition a better object for studying the ongoing neurotransmission even if one has to rely on 'yesterday's' events. Several neurotransmitter systems at different CNS levels operate concomitantly and may therefore be difficult to study in detail; however, again with reference to the basic sciences, we have learned more about some of the steps involved (9).

CSF has so far been proven to be a suitable body fluid for studying central nervous synaptic activity in humans (10). Neurotransmitters released into the CSF can be traced and studied. This has been done in patients with fibromyalgia. The procedure involves a lumbar puncture of the patient followed by a spinal tap of CSF. This substrate is then subjected to specific biochemical analysis.

It is important to consider whether the CSF peptide levels found to be different from those of painless healthy volunteers reflect a pathological condition or just a selection bias. In the pilot studies done on the subject and referred to in this review no correlation was found between pain severity and other relevant pain parameters. Studying a pain versus a nonpain population represents a certain selection. The only clear and statistically significant difference found so far is the presence of pain in the patient groups. For details the original studies referred to in this review should be consulted.

\section{OPIOID PEPTIDES AND CHRONIC PAIN}

Opioid peptides derive from three genetically distinct precursor hormones (proopiomelanocortin, proenkephalin A and proenkephalin B), each with a unique distribution regarding both different cell types and neuronal pathways. The minimum sequence necessary for opioid activity is the enkephalin unit (Tyr-GlyGly-Phe-X, X = Leu or Met). The opioid activity is related to the $\mathrm{C}$ terminal and may be increased by elongating the enkephalin sequence, eg, the Met-enkephalin-Arg ${ }^{6}-\mathrm{Phe}^{7}$ peptide (11).

Of special interest, from proopiomelanocortin is derived beta-endorphin, a peptide in relatively stable quantities in the CSF. However, studies have shown that patients suffering from certain conditions of cancer pain have lower CSF levels than healthy volunteers (12). Migraine with interparoxysmal headache alone and in combination with depression yielded lower CSF levels compared with healthy volunteers (13).

Of the two proenkephalin A products, Leu- and Met-enkephalin, the latter is most frequently analyzed. It has been reported that Met-enkephalin levels are increased in CSF from patients with endogenous depression (14) and patients with Parkinson's disease (15). Regarding the relation of this peptide to pain modulation, it was found that acupuncture-like treatment of chronic pain patients is followed by an increase in the CSF levels of Metenkephalin $(16,17)$.

Very few studies on pain patients have been performed so even if animal studies point to the enkephalins as being important for pain modulation more studies are required on the different pain conditions before conclusions can be made. Future research may provide the answer as to whether there are different levels of enkephalins found within the several pain conditions we know today. Therefore, this field still remains relatively unknown and open for more studies. The pain conditions to be studied also need to be more thoroughly described and the various methodologies used for analysis of the enkephalins need to be standardized in order to make comparisons between results from the different laboratories possible.

The proenkephalin B or prodynorphin precursor seem to process not only dynorphins but also Leu-enkephalin (11). Thus it seems that the different precursor systems under certain conditions may overlap as to specific peptide processing. Even though there are relatively few studies, dynorphin $\mathrm{A}$ is the proenkephalin B peptide that has been studied most (11).

One problem is that proenkephalin B peptides are found in very low concentrations in human CSF. Of these peptides dynorphin $\mathrm{A}$ is a major one. It also reacts with a rather specific antiserum directed against its $C$ terminal; therefore measurement of dynorphin A appears as the only option so far (11). As more sensitive techniques are developed other peptides may take its place as the expression of dynorphin system activity. Dynorphin has been linked to inflammatory pain since it has been demonstrated that induced inflammation causes a marked increase in preprodynorphin mRNA $(7,8)$.

It has been recently demonstrated that dynorphin A can also act as an endogenous mediator in a descending antianalgesic system interacting with serotonin $(18,19)$. Results from animal studies after intrathecal administration of dynorphin $\mathrm{A}$ have 
confirmed these antianalgesic properties which seem rather specific to dynorphin A (18).

\section{SUBSTANCE P AND CHRONIC PAIN}

Far from everything is known about the properties of this undecapeptide. It has been established that it probably is the main peptide transmitter substance in the afferent nonmyelinated $\mathrm{C}$ fibres (9). C fibres conduct the majority of the 'second pain' or pain of an aching and burning character. Substance P has sensitizing properties and seems crucial for the development of allodynia and hyperalgesia (9). Substance P is a strong vasodilator that coexists in the nerve terminals with calcitonin gene related peptide (11). Together with histamine these peptides probably are responsible, if not for all, at least for a greater part of the hyperemia associated with inflammatory reactions (9). This links substance $\mathrm{P}$ not only to the forwarding of certain afferent $\mathrm{C}$ fibre conducted impulses but also to inflammatory pain conditions.

Other conditions in which the CSF levels of substance P have been measured are schizophrenia and severe depression. For both disorders the levels obtained were much higher compared with those found in healthy controls (20).

The interaction between substance $\mathrm{P}$ and noradrenaline seems to play a key role in the process of sensitization since blocking the noradrenergic activity causes less effective substance $\mathrm{P}$ mediated C fibre impulse conduction in the sensitized afferent system (9). This has special interest when trying to understand the mechanisms of how sensitization may alter the properties of normal pain impulse conduction. The sympathetic nervous system is of course responsible for noradrenergic activity at the peripheral sites. Substance P mediated neuronal activity is blocked at the first central nervous synapse level by enkephalinergic interneuronal inhibition. As for other inhibitory mechanisms operating at this level, the enkephalinergic interneurons most likely cause presynaptic inhibition. Whether they also make postsynaptic connections remains a matter of controversy.

\section{OPIOID PEPTIDES AND FIBROMYALGIA}

Beta-endorphin: CSF levels of beta-endorphins in patients with fibromyalgia were measured and found not to be different compared with levels in healthy controls (21). Some may say this is no surprise since previous studies of the peptide in serum also showed levels similar to those in healthy controls $(22,23)$. However, due to its close relation to the extracellular synaptic fluid, the author and colleagues (21) chose CSF instead of serum because they believed that the former probably better reflects activity in the CNS. In addition, there is also a higher possibility of uncontrollable cross-reactivity which can influence the results if serum instead of CSF were chosen as substrate for the measurements.

Enkephalins: One of the more potent enkephalins is the heptapeptide Met-enkephalin-Arg ${ }^{6}-\mathrm{Phe}^{7}$. In a pilot study this peptide was found to be significantly elevated in CSF aliquots from patients with fibromyalgia compared with healthy controls (24). Since enkephalinergic interneurons are known to modulate afferent substance P mediated activity (9) this observation may reflect an altered activity in the enkephalinergic interneurons at the spinal cord level.
In view of the results pointing at elevated CSF levels of substance $\mathrm{P}$ in patients with fibromyalgia, elevated levels of Metenkephalin could be the pathophysiological response to afferent overactivity. However, more extensive studies in this area are needed before a clearer picture of what happens can be formed.

Most likely one major task for enkephalinergic intervention at the spinal cord level is to prevent the forwarding of an excessive amount of afferent noxious impulses. Such activity may also be the result of a sensitization process in the periphery or due to reduced presynaptic inhibitory feedback at the level of the first central nervous synapse (9). As no specific nociceptive cause has been demonstrated in fibromyalgia so far (2), the hypothesis involving sensitization and/or presynaptic inhibition as likely contributors to the pain in fibromyalgia is favoured. It was also found that the Met-enkephalin-Arg ${ }^{6}-\mathrm{Phe}^{7}$ levels correlated significantly $(\mathrm{P}=0.03)$ with the previously measured beta-endorphin levels (21). This correlation between two peptides known to operate mainly in two different regions within the CSF opens the door for some very interesting, although hypothetical, interpretations. Beta-endorphin operates more at the higher central nervous level and Met-enkephalin has a dominant role as transmitter in some of the spinal interneurons. A positive correlation could reflect the activity in an anatomical link between two regions involved in the processing of pain, this link being represented by the monoaminergic bulbospinal tracts. Clearly this is speculative and simplified; however, based on present pharmacological knowledge, theoretically such an hypothesis has a certain bearing.

Dynorphin A: Results obtained from the pilot study by the author and co-workers (24) also demonstrate that CSF levels of dynorphin A were significantly elevated compared with controls. These dynorphin levels also correlated significantly $(\mathrm{P}<0.001)$ with the Met-enkephalin levels, but not with any other peptide measured in the CSF from patients with fibromyalgia. Those authors do not know how to interpret these latter results, except for the fact that all three major opioid peptide systems seem to be more or less involved in fibromyalgia. More information is needed before anything can be said regarding whether these observations are specific for pain in fibromyalgia. Animal experiments have shown that chronic inflammation causes an increase in the levels of preprodynorphin mRNA $(7,8)$. Whether this means that the pain in fibromyalgia should be classified as inflammatory remains to be seen. There is no biochemical parameter indicating inflammation in fibromyalgia although clinically there may often be a certain resemblance to the more classical inflammatory rheumatological disorders.

\section{SUBSTANCE P AND FIBROMYALGIA}

The first study where substance $\mathrm{P}$ was measured in CSF from patients with fibromyalgia was published in 1988 (25). The reason for selecting substance $\mathrm{P}$ was the clinical observation and description of the pain picture in fibromyalgia. Knowledge from the basic pharmacological sciences, the patients' complaints of aching and burning, increased toothache-like pain after tender point examinations and possible inflammatory involvement indicated the possible involvement of substance P. The results obtained pointed at a threefold increase of substance $\mathrm{P}$ in CSF from pa- 
tients with fibromyalgia compared with healthy controls (25). These results have later been confirmed by a different research group (26). What these elevated substance P levels actually reflect may have and probably does have several answers. One possibility is that the elevated levels reflect increased afferent activity perhaps related to sensitization processes. Alternatively, it could be the result of decreased activity in the inhibitory mechanisms operating at the level of the first central nervous synapse. Other possibilities may involve factors related to enzymatic activities interfering with synthesis and degradation of the peptide. It has been shown that the synthesis of substance P is not necessarily something that only occurs in the neurons. The CSF is capable of synthesis of substance $\mathrm{P}$ from a substance P-Gly ${ }^{12}$ precursor by alpha-amidation (27). It is suggested that important events related to the pain in fibromyalgia patients occur in relation to the first central nervous synapse at the level of the spinal cord.

Substance $\mathrm{P}$ is not the only peptide thought to be involved with pain in fibromyalgia at this level. There are several other candidates that need to be considered in attempts to make a complete hypothesis regarding what really happens when pain is experienced in fibromyalgia.

\section{FUTURE RESEARCH DIRECTIONS Sympathetically maintained or independent pain}

Some of the symptoms in fibromyalgia are similar to those seen during abnormal activity in the sympathetic nervous system, eg, a Raynaud-like phenomenon $(25,28)$. In fibromyalgia one study has demonstrated that the pain, to a great extent, is relieved by sympathetic blockade (29), and there is also evidence suggesting that these patients have a sympathetic dysfunction $(5,6,30)$. One study found that there were signs of increased adrenergic activity and, at the same time, decreased cholinergic activity in fibromyalgia patients compared with healthy controls. Elevated concentrations of platelet alpha- 2 adrenergic receptors were also found in fibromyalgia patients with a concomitant Raynaud's phenomenon.

Based on results from a few pilot studies there seems to be an association between pain in fibromyalgia and sympathetic nervous activity $(5,6,30)$. According to Nathan (31) there are two reasons to suspect sympathetic nervous system involvement: when the control of sympathetically innervated structures is abnormal; and when the states are temporarily relieved by sympathetic blocks. In other words there is a possibility that at least part of the pain in fibromyalgia patients can be classified as sympathetically maintained pain.

\section{Plasticity changes}

Patients' descriptions of how the chronic pain may start locally and continue to spread symmetrically after a relatively short time, segment by segment, led to speculation regarding changes in plasticity as a plausible explanation. No specific study has been done in this field. Still, we are continuously searching for an explanation for such a pattern in the evolution of pain. Microcirculatory disturbances and ischemia may very well be limited to a segmental level of the spinal cord. Ischemia might cause neuronal destruction which in turn will force the nervous impulse barrage to make use of alternative pathways. One may foresee severe complications following such microanatomic alterations. Could it be that the appearance and persistence of fibromyalgic tender points actually represent areas of secondary hyperalgesia? If so, this makes tender points and the generally increased sensitivity a central nervous phenomenon rather than a peripheral myopathological event. The important question is whether there is anything that can back up these rather liberal speculations. There is - preliminary results from a study in which dynorphin converting enzyme activity has been studied point to the possibility that this activity is lower in fibromyalgia patients. The released dynorphin is not degraded rapidly enough, leaving the nonopioid properties of dynorphin to act undisturbed with the possibility of neuronal cell death as the final outcome. Such processes may very well occur at both local and regional levels $(32,33)$.

\section{The relevance of fatigue}

Fibromyalgia patients experience fatigue more easily than control subjects with and without muscular pain (34). Studies have also shown that both isometric and isokinetic maximal voluntary muscle strength are lower in patients with fibromyalgia compared with healthy controls, and that the more tender the points in a patient, the lower the muscle strength seems to be. In a study using transcutaneous superimposed electrical impulses to test the degree of submaximal muscular contraction (34), it was concluded that in fibromyalgia there must be a major central nervous component explaining the reduced muscle strength. What this component is remains to be seen.

\section{Pharmacological investigations}

Once differences in the transmitter levels have been described, important questions follow, eg, what precedes these differences at the receptor level and how may this influence signal transduction? No studies have been done on receptor mechanisms with respect to fibromyalgia.

Possible mechanisms involving inhibition or up- and downregulation of receptors in this chronic pain condition are also unknown. Clinical examination of the patients may help by outlining a picture that is associated with sensitization processes, although there is so far no clear evidence to support this hypothesis. The present view regarding neuropeptides and fibromyalgia is based on results from investigations referred to in this review.

A number of peptides are thought to be involved in the forwarding of signals eventually resulting in the sensation of pain. We do not know much about the clinical significance of these substances. As for future research, it is of importance that the findings in question are reproduced independently by other research groups as in the case of elevated CSF levels of substance $P$ $(25,26)$. In addition, pharmacological studies of synaptic activity at different levels are strongly needed if we are to reveal more about the secrets behind the pain in fibromyalgia, as well as in other chronic pain conditions. Finally, new techniques currently being developed will certainly provide more of the information needed for our understanding of chronic pain. 
ACKNOWLEDGEMENTS: The author thanks the Grethe Harbitz Legacy for Rheumatic Research for financial support.

\section{REFERENCES}

1. Wolfe F, Smythe HA, Yunus MB, et al. The American College of Rheumatology 1990 criteria for the classification of fibromyalgia. Arthritis Rheum 1990:33:160-72.

2. McCain GA. The clinical features of the fibromyalgia syndrome. In: Værøy H, Merskey H, eds. Progress in Fibromyalgia and Myofascial Pain. Pain Research and Clinical Management, vol 6. Amsterdam: Elsevier Science Publishers, 1993.

3. Henriksson KG, Bengtsson A, Lindman R, Thornell LE. Morphological changes in the muscle in fibromyalgia and chronic shoulder myalgia, In: Værøy H, Merskey H, eds. Progress in Fibromyalgia and Myofascial Pain. Pain Research and Clinical Management, vol 6. Amsterdam: Elsevier Science Publishers, 1993.

4. Bengtsson A, Henriksson KG, Larsson J. Reduced high-energy phosphate levels in the painful muscles of patients with primary fibromyalgia. Arthritis Rheum 1986;29:817-21.

5. Værøy H, Qiao ZG, Mørkrid L, Førre Ø. Altered sympathetic nervous system response in patients with fibromyalgia (fibrositis syndrome). J Rheumatol 1989;16:1460-5.

6. Qiao ZG, Værøy H, Mørkrid L. Electrodermal and microcirculatory activity in patients with fibromyalgia during baseline, acoustic stimulation and cold pressor tests. J Rheumatol 1991;18:1383-9.

7. Ruda MA, Iadarola MJ, Cohen LV, Young WS III. In situ hybridisation histochemistry and immunohistochemistry reveal an increase in spina dynorphin biosynthesis in a rat model of peripheral inflammation and hyperalgesia. Proc Natl Acad Sci USA 1988;85:622-6.

8. Weihe E, Millan MJ, Hollt V, Nohr D, Herz A. Induction of the gene encoding pro-dynorphin by experimentally induced arthritis enhances staining for dynorphin in the spinal cord of rats. Neuroscience 1989;31:77-95.

9. Fields HL. Pain. New York: McGraw-Hill, 1987.

10. Terenius L. Endogenous opioid peptides and analgesia. Annu Rev Pharmacol Toxicol 1978;18:189-204.

11. Nyberg F, Vaerøy H, Terenius L. Opioid peptides and substance $P$ in the cerebrospinal fluid: Regulation and significance to pain. In: Olesen J, Edvinsson L, eds. Basic Mechanisms of Headache. Amsterdam: Elsevier Science Publishers, 1988.

12. Tsubokawa T, Yamamoto T, Katayama Y, Hirayama T, Sibuya H. Thalamic relay nucleus stimulation for relief of intractable pain. Clinical results and beta-endorphin immunoreactivity in the cerebrospinal fluid. Pain 1984;18:115-26.

13. Nappi G, Facchinetti F, Martignoni E, Petraglia F, Bono G, Genazzani AR. CSF beta-endorphin in headache and depression. Cephalalgia 1985;5:99-101.

14. Loeb C, Albano C, Serrati C. Studio dei livelli liquoriali della leucinencefalina e della metioninencefalina in pazienti con alterazioni comportamentali, Schwiz Arch Neurol Neurochir Psychiatr 1984;134:29-40.

15. Pezzoli G, Panerai AE, Di Giulio A, Longo A, Passerini D, Carenzi A. Methionine enkephalin, substance $\mathrm{P}$ and homovanillic acid in the CSF of Parkinsonian patients. Neurology 1984;34:516-9.

16. Clement-Jones V, McLoughlin L, Lowry PJ, Besser GM, Rees LH, Wen HL. Acupuncture in heroin addicts: changes in met-enkephalin and beta-endorphin in blood and cerebrospinal fluid. Lancet 1979;ii:380-3.
17. Clement-Jones V, McLoughlin L, Tomlin S, Besser GM, Rees LH, Wen HL. Increased beta-endorphin but not met-enkephalin levels in human cerebrospinal fluid after acupuncture for recurrent pain. Lancet 1980;ii:946-9.

18. Silberring J, Castello ME, Nyberg F. Characterization of dynorphin A-converting enzyme in human spinal cord. J Biol Chem 1992;267:21324-8.

19. Sharma HS, Nyberg F, Olsson Y. Dynorphin A content in the rat brain and spinal cord after a localized trauma to the spinal cord and its modification with p-chlorophenylalanine. Neurosci Res 1992;14:195-203

20. Rimon R, Le Greves P, Nyberg F, Heikkila L, Salema H, Terenius L. Elevation of substance P-like peptides in the CSF of psychiatric patients. Biol Psychiatry 1984;19:509-16.

21. Værøy H, Helle R, Førre Ø, Kåss E, Terenius L. Cerebrospinal fluid levels of beta-endorphin in patients with fibromyalgia. J Rheumatol 1989;15:1804-6.

22. Hamaty D, Valentine JL, Howard R, Howard CW, Wakefield V, Patten MS. The plasma endorphin, prostaglandin and catecholamine profile of patients with fibrositis treated with cyclobenzaprine and placebo: a 5-month study. J Rheumatol 1989;16(Suppl 19):164-8.

23. Yunus MB, Denko CV, Masi AT. Serum beta-endorphin in primary fibromyalgia syndrome: a controlled study. J Rheumatol 1986;13:183-6.

24. Værøy H, Nyberg F, Terenius L. No evidence for endorphin deficiency in fibromyalgia following investigation of cerebrospinal fluid (CSF) dynorphin A and Met-endorphin in patients with fibromyalgia (fibrositis syndrome). Pain 1991;46:139-43.

25. Værøy H, Helle R, Førre Ø, Kåss E, Terenius L. Elevated CSF levels of substance $\mathrm{P}$ and high incidence of Raynaud's phenomenon in patients with fibromyalgia: new features for diagnosis. Pain 1988;32:21-6.

26. Russell IJ, Orr MD, Littman B, et al. Elevated cerebrospinal fluid levels of substance $\mathrm{P}$ in patients with the fibromyalgia syndrome. Arthritis Rheum 1994;11:1593-601.

27. Værøy H, Nyberg F, Franzen H, Terenius L. Characterization of a substance P-Gly amidating enzyme in human cerebrospinal fluid. Biochem Biophys Res Commun 1987;125:244-50.

28. Dinerman H, Goldenberg DL, Felson DT. A prospective evaluation of 118 patients with the fibromyalgia syndrome. J Rheumatol 1986;13:368-73.

29. Bengtsson A, Bengtsson M. Regional sympathetic blockade in primary fibromyalgia. Pain 1988;33:161-7.

30. Bennett RM, Clark SR, Campbell SM, et al. Symptoms of Raynaud's syndrome in patients with fibromyalgia. Arthritis Rheum 1991;34:264-9.

31. Nathan P. Pain and the sympathetic system. J Auton Nerv Syst 1983;7:363-70.

32. Long JB, Petras JM, Mobley WC, Holaday JW. Neurological dysfunction after intrathecal injection of Dynorphin $\mathrm{A}(1-13)$ in the rat. II. Nonopioid mechanisms mediate loss of motor, sensory and autonomic function. J Pharmacol Exp Ther 1988;246:1167-74.

33. Long JB, Kinney RC, Malcolm DS, Graeber GM, Holaday JW. Intrathecal dynorphin A (1-13) and dynorphin (3-13) reduce rat spinal cord blood flow by non-opioid mechanisms. Brain Res 1989;436:374-9.

34. Jacobsen S, Høydalsmo OJ. Experimental research on muscle physiology during work and exercise: relation to the development of musculoskeletal pain and fatigue. In: Værøy H, Merskey H, eds. Progress in Fibromyalgia and Myofascial Pain. Pain Research and 
Clinical Management, vol 6. Amsterdam: Elsevier Science Publishers, 1993. 


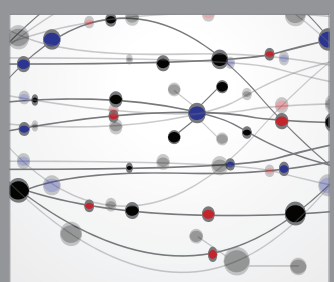

The Scientific World Journal
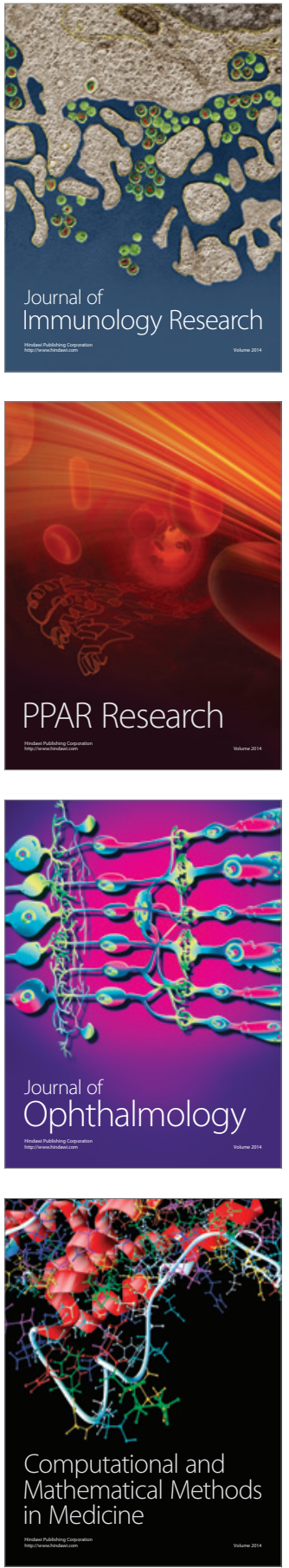

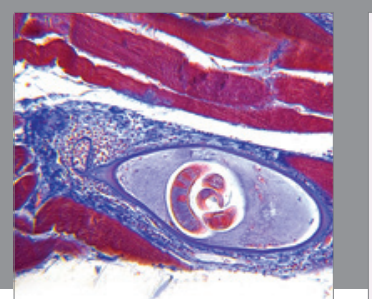

Gastroenterology Research and Practice

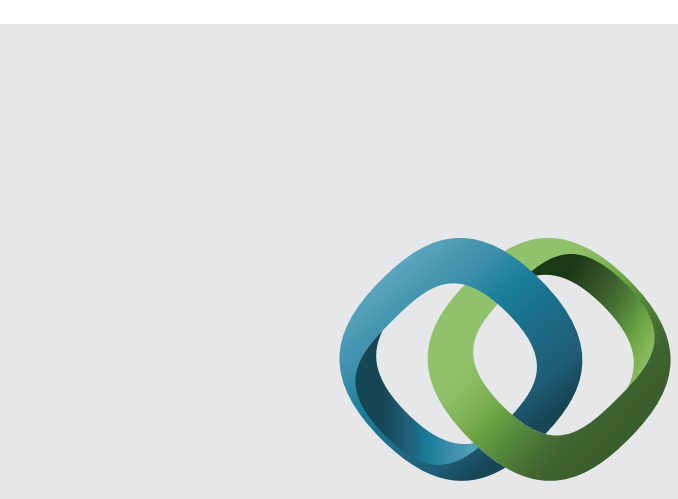

\section{Hindawi}

Submit your manuscripts at

http://www.hindawi.com
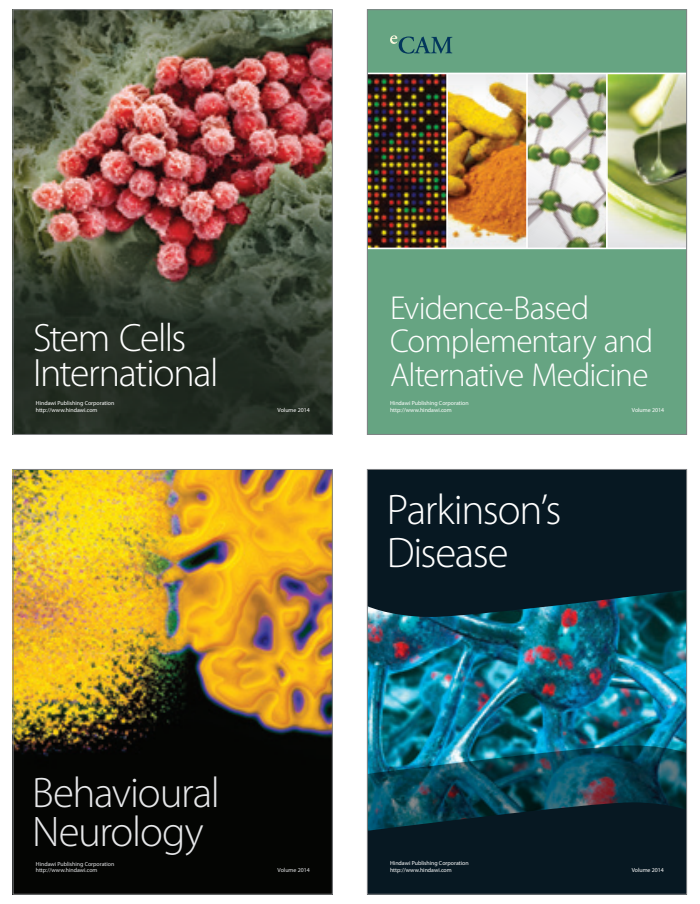
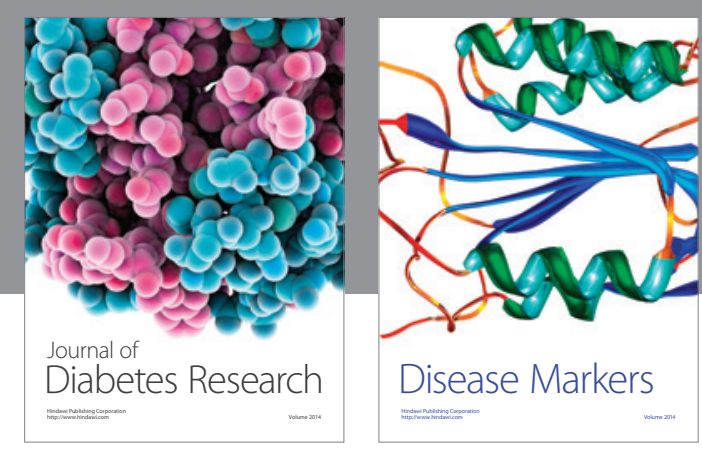

Disease Markers
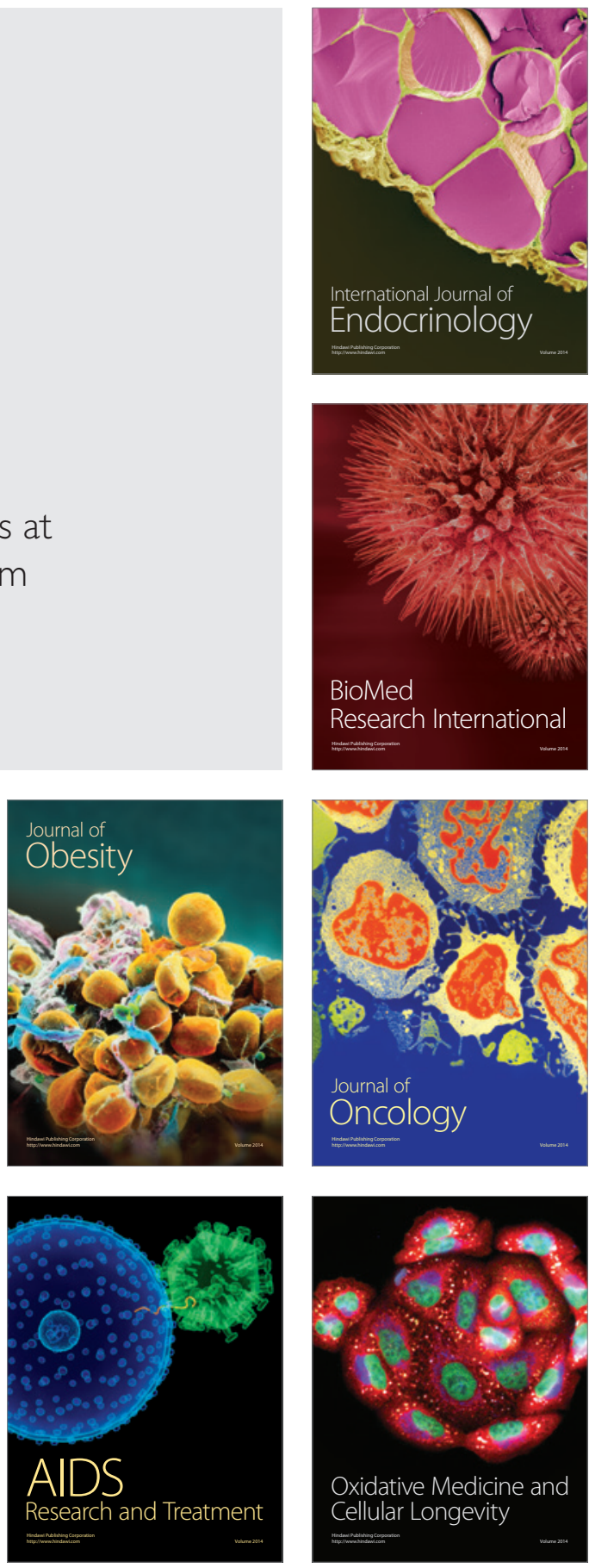